\title{
PRESENCIA AFRICANA EN EL PERÚ
}

\section{Eduardo Arroyo}

\section{Resumen}

El autor plantea que África es la cuna de la humanidad y en ese sentido, todos seríamos afro-descendientes. Podríamos hablar de una África árabe y una negra. Nuestra vinculación con este continente procede de los invasores europeos que llegan a nuestros territorios en 1532. Ellos habian tenido ocho siglos de dominación árabe en sus reinos. Desde entonces multitud de expresiones de la cultura y vida africana se dan en nuestras culturas influyendo en nuestra multiculturalidad, multilinguismo y mestizaje. Así hay que considerar el álgebra, matemáticas, ajedrez; la alimentación y sus ingredientes; música, baile, literatura, deportes.

Palabras Clave: África, Perú, cultura, afrodescendiente.

\section{Abstract}

África is the origin of the mankind . In that sense, we all are afro-descendants.

There are an arabian Africa and another negro Africa. We received their influence since european invasion over our country in 1532. Since then, many african elements have a big influence on our multicultural configuration. We can consider the algebra, mathematics, the chess; ingredients of food; music, dancing, literature and sports.

Key words: Africa, Perú, culture, afro-descendant 
Hablar de África es hablar de cosas mayores. Es referirse a la cuna de la humanidad, a los primeros hominidos encontrados en el corazón de dicho continente, sea en Kenia, en Kinshasa, en El Congo, en Uganda, en Zaire, en Tanzania con antepasados humanos de 4'000,000 años a.C.

Los javaneses con sus 600,000 a.C., o el Sinantropus Pekinensis, de medio millar de años de antigüedad, y los europeos del 250,000 a.C. al 25,000 a.C., son más recientes.

Influenciados por su antigüedad, todos llevamos en nuestro ADN elementos de la herencia africana, más las mujeres cuya estructura mitocondrial las lleva a tener la capacidad de almacenar mayor trascendencia del pasado. En un sentido amplio pues, todos somos afro-descendientes.

África es un continente inmenso. Los europeos mirando el mundo desde su particular ubicación geográfica y haciendo gala de su reconocida visión eurocéntrica, tuvieron cerca del Mar Mediterráneo a la zona del Magreb (Marruecos, Mauritania, Argelia, Libia) que en una época fue una sola unidad territorial, y denominaron Medio Oriente a los territorios que colindan con el Asia (Egipto, Arabia, Irak, Irán, Qatar, Omán, Sudán, Palestina, Israel, Jordania, Siria, Líbano),cuna de las primeras grandes civilizaciones sedentarias y de las religiones monoteístas: judaismo, islamismo y cristianismo.

No sería incorrecto proyectar una África árabe y una África negra.
Los tiempos antiguos recuerdan en el África norte una gran movilización árabe hacia el oeste, dejando huellas de su cultura, de su religión, de su lenguaje en los países del África nor-occidental bañados por el Mar Mediterráneo y en los países del Medio Oriente. Se arabizaron esos territorios y asumieron la religión islámica. Esa expansión llegó a Europa conquistando parte de ella. Los reinos de la Península Ibérica, no España que no existía por ese entonces, cayeron sojuzgados por la influencia musulmana durante ocho siglos.

Los invasores europeos que llegaron a América del Sur y Central nos trajeron esa heredad, la que se instala en nuestros genes así como en nuestra cultura. Nos lo recuerda el lenguaje, siendo todas las palabras que empiezan con "al" de origen árabe, que suman en conjunto unos 1,500 vocablos. Hemos heredado muchos condimentos de nuestra comida, sus frituras; dulces; grandes inventos: el álgebra, la matemática, la astronomía, el ajedrez, el arte, el diseño, la ojiva, el arco de medio punto, como el arte mudéjar.

Pero la otra África también llegó a América Latina y el Caribe, solo que esclavizada. Llegaba del corazón continental africano representada por individuos a los que se negaba su condición de personas, privándoselos de la libertad,de la igualdad y maltratándoselos hasta la saciedad. Fueron cosificados, es decir, considerados como objetos. La renta en trabajo es la más arcaica en la 
historia de la humanidad y condena al esclavo a trabajar a tiempo completo, negándole su esencia humana, diferente a la renta en especies o productos del siervo de la época feudal y la renta en salario del capitalismo y la modernidad.

\section{DOS PERÚS}

152 dos de desarrollo humano. La civilización inca tiene hegemonía en el territorio nacional entre los años 1432 d.C. y 1532 d.C., fecha en que la invasión europea corta su hegemonía en estos predios, que llegaban hasta Pasto en Colombia y a concepción en Chile.

Nuestro imperio con quince millones de personas en 1525, no pasaba de un millón y medio en 1571 , con Toledo $^{2}$. Esta caída demográfica extrema fue muy estrepitosa en la costa. Algunos historiadores la atribuyen a la tríada trabajo-dieta-epidemia, predominando el contagio letal de enfermedades traídas del Viejo mundo, contra las que la población andina no había generado resistencias. A ello hay que añadir la ruptura de la unidad básica, la familia andina, la que había estado arraigada a la tierra y que se vio compelida a desplazarse a nuevos territorios en función a otros intereses económicos, ininteligibles para los aborígenes de estos suelos. Lo que sobrevivió fue la depresión colectiva de un modelo comunitario avasallado por los valores individualistas de la cultura europea.

A partir de entonces, el hombre de campo no quiso seguir reproduciéndose por las condiciones de negación de su civilización, lo que los hizo perder el interés de vivir. A su vez, con la mita minera se practicó el mayor genocidio que recuerda la historia humana, a entender de Tzvetan Todorov ${ }^{3}$. España, en disputa con Inglaterra y Francia por el dominio del concierto internacional de naciones en el sistema mercantilista que reposaba en la 
tenencia de oro y plata, no encontró otra vía que deshacer nuestra matriz cultural, colonizarnos y, cuando no tuvo más peruanos, trajo a los africanos, los que no pudiendo soportar los climas fríos de la sierra, se aclimataron en el litoral.

\section{LA POBLACIÓN NEGRA EN EL PERÚ}

Nos dice José Carlos Mariátegui, que "La tendencia de los españoles a establecerse en la costa ahuyentó de esta región a los aborígenes a tal punto que se carecía de brazos para el trabajo. El Virreinato quiso resolver este problema mediante la importación de esclavos negros, gente que resultó adecuada al clima y las fatigas de los valles o llanos cálidos de la costa, e inaparente, en cambio, para el trabajo de las minas, situadas en la sierra fría....El negro fue dedicado al servicio doméstico y a los oficios. El blanco se mezcló fácilmente con el negro produciendo este mestizaje uno de los tipos de población costeña con características de mayor adhesión a lo español y mayor resistencia a lo indigena..."

Refiere Luis Eduardo Valcárcel, que "El negro que arribó al Perú con Pizarro fue siempre esclavo, hasta su liberación hace apenas cien años. El tráfico esclavista mantuvo un fluir ininterrumpido de "piezas de ébano" (así se denominaba esa "mercadería”). Procedentes los cargamentos del África occidental, llegaban a nuestros puertos para desparramar su tinto contenido en los valles de la costa. Venian a reemplazar a los habitantes indios...La introducción de cultivos como la caña de azúcar- a semejanza, ahora, del algodón o el lino- con ánimo puramente capitalista, extinguió el de los productos alimenticios autóctonos: el maíz, el frijol, el maní, la yuca, etc. Las numerosas poblaciones de indios se extinguieron como natural consecuencia. A reemplazarla vinieron los negros, simples cosas, introduciéndose, con su secuela trágica, el régimen esclavista. Si los indios en la sierra vivían en servidumbre feudal, los negros en la costa recordaban las ergástulas griegas y romanas...Lima, durante el virreinato, es la ciudad con mayor porcentaje de población negra...La sierra no fue propicia a la introducción del negro, ni aun la selva..."5.

A diferencia de Hernán Cortés en México, dueño de grandes dotaciones de esclavos africanos, Francisco Pizarro no tuvo tantos. Los esclavos africanos llegaron al Perú con Pizarro antes de firmarse la capitulación de Toledo. Estuvieron del lado del conquistador ibérico. Se debe recordar que es un inmigrante el que salva a Diego de Almagro en Pueblo Quemado. Hubo numerosas tropas de esclavos en las guerras de los encomenderos.

Los negros fueron carne de cañón y estuvieron sea del lado de los caudillos reales sea del lado de los rebeldes enfrentados al rey. Es un africano el que decapita en Añaquito al virrey Blasco Núñez de Vela. Posteriormente, participaron en las guerras de Túpac Amaru y en las guerras independentistas.

Llegaron varios tipos de africanos negros a nuestro país. Al perderse el recuerdo de su verdadero nombre 
africano, se los apellidaba por su origen tribal: mandingas, congos, cabo verdes, angolas, carabalíes, zapes, aras, folupos, pigmeos, etc.

El comercio y la guerra promueve la llegada masiva de esclavos negros después de 1570. Toda la producción del país era exclusivamente basada en la fuerza de trabajo de los esclavos y la de los indios. Pablo Macera refiere que "En lo que se refiere a la agricultura, hubo en primer lugar, la esclavitud que entre nosotros estuvo localizada en la costa, sobre todo en el norte y centro, y, preferentemente, dedicada a las plantaciones de caña; en segundo lugar a la vid (al sur de Lima) y en proporción mucho menor a las huertas y panllevar..."

Flores Galindo sostiene que la mayoría de esclavos se concentró en la costa y centralmente en Lima. Era una esclavitud urbana. Hacia 1636, los esclavos negros fueron mayoria, con 13,620 habitantes, por encima de los 10,758 españoles; aunque no llegaban a tantos como Venezuela $(87,000)$ o el Caribe (proporción 10 a 1). La mayoría estaba en la costa y un 60\% en Lima. Llegó un momento en que la ciudad de Lima tenía la mayor parte de su población conformada por esclavos. Llegó a ser una ciudad negra, que a su vez tenía la élite virreinal más numerosa e importante de Hispanoamérica ${ }^{7}$.

La gran mayoría de esclavos africanos fueron concentrados en el interior de las murallas de la Ciudad de los Reyes, constituyendo el $25.6 \%$ de la población urbana, un aporte significativo al Perú colonial.
Dentro de las murallas de Lima, terminarian predominando en las parroquias de La Catedral y San Lázaro. Unos vivieron en el centro mismo de la ciudad y otros, hacinados y excluídos en el barrio de San Lázaro, barrio de los marginados, incluyendo españoles pobres que llegaban a estas comarcas. Luego de su concentración en San Lázaro, los africanos fueron recluidos en un galpón público en el barrio de Malambo (Lima), para posteriormente ser llevados a diferentes partes del país.

Los africanos no soportaban el frío de nuestra serranía, en donde vivía el grueso de la población peruana. De alli ese dicho criollo "gallinazo no canta en puna". La mayoría de esclavos negros estuvieron asentados, aparte de los que estaban en Lima, en los valles azucareros del norte (Saña), Nepeña (Ancash), zonas azucareras y vitivinícolas del sur (Cañete, Pisco, Chincha).

\section{ORÍGENES DEL RACISMO EN EL PERÚ}

La racialización oprobiosa es una herencia ibérica. La discriminación racial vigente en nuestro país tiene su origen en el pasado colonial. Aníbal Quijano nos dice en un texto denominado "Qué tal raza", que lo que hubo en el mundo prehispánico fueron diferencias étnicas y culturales, pero no raciales. El racismo es de génesis colonial ibérica.

China había sido potencia, pero nunca racializó las costumbres ni ha- 
bló de razas superiores y, sin embargo, pese a la fraternidad universal que predicaba el cristianismo, los cristianos llegaron con la espada y la biblia a sojuzgar. Necesitados de oro y la plata, devastaron nuestros territorios en el acto genocida más grande la historia.

Al esclavo no se le consideraba persona sino meramente un objeto, no un animal humano sino un animal sin alma. Había un valor de uso en tenerlo. Se le quitó la calidad de persona; el esclavo era considerado una bestia de carga que pagaba su existencia trabajando a dedicación exclusiva. Se le adjudicaba la misma dignidad que un caballo.

Si era nacido en América, se lo denominada ladino o criollo. Si recién llegaba del África, era un bozal. No se podía comprar gelofes, es decir, negros africanos con influencia islámica. Así, vemos una doble discriminación, la racial y la religiosa.

Tener la mayor cantidad de esclavos fue en la colonia el modo principal de ascender en status social, secundado con la tenencia de la mayor cantidad de caballos, los mejores carruajes, los mejores trajes. Los esclavos costaban más que en Buenos Aires.

Los negros esclavos de entre 20 a 35 años de edad, $1.70 \mathrm{mts}$ y de buena salud, eran considerados piezas de ébano, así se los llamaba. El sistema más eficaz consistía en lograr obtener ganancias que sobrepasaran a la inversión inicial (valor del esclavo). Al hacer que el esclavo fuese más productivo se acortaba la duración de su vida.
En Europa se decía que los negros eran hijos de Cam. Este era uno de los hijos de Noé, junto a Sem, y Jafet. Se calificó a Cam de inmoral y así se justificó el esclavizar a sus supuestos descendientes a los que caracterizó de disolutos.

La tradición judeo cristiano racializaba la belleza y la virtud como el pecado. Lo negro era lo pecaminoso. Por ello, no tenemos ángeles negros, si bien Mackandall ${ }^{9}$ soñaba con un paraíso y un mesías negro, como que en los países asiáticos pueden imaginar un cristo chino, siberiano, etc.

La virtud ha sido tradicionalmente blanca. En el Perú, muchos niños dibujan un dios siempre blanco, de largas barbas, para señalar su eternidad; nunca un dios cholo, mestizo, trigueño, como debería corresponder.

Lo negro fue satanizado y lo árabe fue excluido en la tradiciones cristianas que nos trajeron los colonizadores ibéricos, los que paradójicamente llegaban cargados de ocho siglos de influencia africana en general y con un mensaje de inclusión y fraternidad cristiana. Ni la influencia africana en nuestras vidas se entendió, ni se cumplió con la utopía cristiana de amar a todos los seres humanos como uno mismo.

En el caso peruano, los negros libertos, al emular a los españoles en el maltrato a los indios, generaron que estos no los miraran bien y se generara desconfianza entre ambos, cuando debió ser al revés, por su calidad de excluidos y potencialmente aliados. 
La alimentación de los africanos fue en base a zango, zapallo, camote, pan, pescado, menudencia de animales, ron, chicha. Esa menudencia y el corazón de la res fritos, son los que dan origen a la fritanguita (anticuchos, choncholies, rachi). Es pues plebeyo el origen de nuestro afamado anticucho $\mathrm{y}$ fritanguita en general, si bien en el África árabe, caso concreto de Marruecos, tienen algo muy parecido al anticucho, no de carne de res sino de ave.

Los esclavos negros eran seleccionados por sus condiciones físicas. Fueron raza de élite biológica. Hoy sabemos que tienen el fenotipo que los hace especialmente diestros para cierto tipo de deporte.

Los negros criollos, eran los nacidos en América; los bozales eran los que no hablaban castellano; los ladinos sí hablaban el lenguaje de Castilla.

La esclavitud permitió una fuerza de trabajo gratuita. Lima se convirtió en una ciudad de negros y mulatos en gran cantidad. Mulato era el hijo de negra con español, y zambo era el hijo de negra con indio. Los esclavos musulmanes fueran negros o árabesberberiscos que llegaron a la Península Ibérica, capturados en las guerras. Habían esclavos mahometanos y negros. En cambio, los moriscos eran españoles de religión musulmana, perseguidos y discriminados en su momento.

Los negros eran marcados para señalar la pertenencia a algún señor. Solo se suspendió la carimba (marcar al rojo vivo) en 1789 , es decir, en fecha cercana a las luchas independentistas.
E1 maltrato los llevó a escapar constantemente ${ }^{10}$. A los escapados se los llamaba cimarrones y formaron pequeños palenques en las cercanías de Lima, dedicados al bandidaje, al vagabundaje. La exclusión social explica este tipo de delincuencia. Asaltaban en las afueras de la ciudad a los carruajes y personas que circularan por allí. Desde entonces, los carruajes coloniales saliendo de Lima rumbo a Agua Dulce, playa de veraneo de los virreyes o a Cantolao en el Callao, hubieron de tener resguardo militar para repeler cualquier intento de asalto.

E1 palenque peruano era equivalente al mocambo o quilombo en Brasil. Aquí el más famoso palenque fue el de Huachipa (1713) dirigido por Francisco Congo, que da nombre a un gran movimiento que cultiva el respeto y el estudio a la ascendencia africana en el Perú.

\section{LA UBICUA PRESENCIA AFRICANA ENTRE NOSOTROS}

Los africanos libertos llegaron a ser artesanos, y, en otros casos, profesionales, como el médico llamado Manuel A. Valdés, a quien el Perú debe un homenaje.

La música al sur de Bujama y El Carmen, en Chincha, que ha venido siendo investigada por el español y músico Micky González, es recogido en el documental "Sigo siendo", de Javier Corcuera, que retrata la identidad del Perú a partir de la música. Allí, junto con la gran vertiente andina en la 
conformación de nuestra identidad, se muestra el zapateo negro, el landó, el panalivio, el alcatraz y otros ritmos negros amestizados que forman parte de nuestra autopercepción nacional y han sido asumidos por el mundo de la música criolla. Hoy consideramos como nuestros a Arturo "Zambo" Cavero, como a Lucha Reyes, a Rosa Guzmán, a Susana Baca, voces de oro; así como a Carlos Hayre, Félix Casaverde, Victoria Santa Cruz, Nicomedes Santa Cruz y familia, Victoria Villalobos.

En nuestra memoria está presente el primer equipo de fútbol del Perú en ser fundado. Inevitable recordar a José María Lavalle, aquel a quien la Guardia Republicana le tocaba una marinera y Lavalle la bailaba dominando la pelota, sin que ningún adversario se la pudiera quitar; el salto felino de "Manguera" Villanueva, la habilidad y caballerosidad de un Vides Mosquera, el cabezaso fulminante de Valeriano López, siempre secundado por don Guillermo Barbadillo, el pique veloz de Juan Joya o Félix Castillo, la velocidad y el taponazo de Alberto Gallardo,el dribling endiablado del Nene Cubillas, el carácter entrador y demoledor de Perico León, acompañado del cerebral Pitín Zegarra, y la cintura firuletera de Julio Baylón, por mencionar a algunas figuras del primer deporte nacional.

Hay mucho de esta herencia en nuestra modalidad de jugar el fútbol, como de bailar. No podemos prescindir del landó, del alcatraz, del panalivio, como aquello que nos viene del trópico cercano, como las guarachas y guajiras cubanas (en las voces de Bienvenido Granda, Ibrahim Ferrer, Benny Moré, Vicentico Valdés, Celia Cruz), buenos en la guaracha como en los boleros cantados por Olga Gui1lot, Toña La Negra y otros, los que son parte de nuestra cultura cotidiana y recuerdos.

En literatura, "Matalaché" de Enrique López Albújar, da vida a ese semental negro, inmenso, cuya función de procrear generaba temor en el mundo blanco, por la fantasía y supuesta mayor potencia sexual de negro. También novelas, como "Piel de fuego" del cineasta Federico García Hurtado, los relatos y ensayos de Luis Roca Torres en el valle de Saña, o Micky Gonzales en el Carmen, con su Akundún. El diplomático José Diez Canseco destaca con "Estampas mulatas" así como "Monólogo desde las tinieblas" de Antonio Gálvez Ronceros, Gregorio Martínez y "Canto de sirena" o su "Tierra de Caléndula"; los personajes Tirifilo y Carita en "Duelo de caballeros", de Ciro Alegría, además de las obras de Julio Carmona y Rafael Santa cruz. El mismo Mario Vargas Llosa nos presenta al negro Bermúdez en su novela "Conversación en la Catedral".

En el Perú, país intensamente mestizo, en el mes morado, la costumbre del Señor de los Milagros es negra. En sus orígenes consistía en sacar al Señor de los Temblores para aplacar a Pachacamac, que lidiaba con Cuniraya y Pariacaca y la tierra temblaba. Igualmente, los santos peruanos más populares representan las antinomias blanca-negra, una es blanca como 
la leche, Rosa de Lima, y otro es un mulato, el querido San Martín de Porras, que da el nombre a un distrito y a una conocida universidad. Limeños, santos milagrosos y amigos, una Rosa ejemplo de estoicismo y vida austera y Martín, que juntaba y daba de comer a perro, pericote y gato, animales tradicionalmente rivales, revelando el corazón de arbitraje que hay en el mundo africano, no necesariamente confrontacional.

Nosotros hemos sido malformados por la visión hollywoodense del África, la que nos planteó que lo que venía del mundo árabe como del África negra, era peligroso. Es el temor de los imperios y la necesidad de Europa de secundar el eurocentrismo como un modo de colonizar nuestro saber y mantenernos colonizados políticamente. Colonialidad del saber y del poder. Visión de la Metro Golden Meyer, de Universal Studies. Esa es la visión del llamado occidente frente a lo desconocido, a lo que ignorantemente ha denominado Oriente. Visión de bárbaros blancos, que esclavizaban a negros en África, la que alcanza su liberación en los años 60 y 70, dejando de ser colonias o semicolonias; pugnando por su soberania.

Los blancos, considerando cultura superior a la eurocéntrica, denostaron la cultura de los otros pueblos del mundo. Sencillamente, despreciaron la cultura de mundos allende sus fronteras, denominándolos bárbaros, semiculturas, culturas folclóricas, sin respeto a su producción, su desarrollo, su avance. Hoy, Naciones Unidas reconoce el estatuto de pueblos originarios y de las culturas originarias, autóctonas, y llama a combatir el racismo en un clima de tolerancia, de respeto a la diversidad. Los pueblos del sur avanzan su propia epistemología, más propia y autónoma ${ }^{11}$. Después de todo, hay muchos modos de hacer ciencia, epistemología, filosofia, medicina, etc.

Ya no tiene cabida la intolerancia hacia el mundo árabe y al mundo africano no árabe. Se está en contra de la cosificación, de la renta en trabajo, la forma más antigua y deshumanizada de la relación entre seres humanos, que despersonaliza, quita la libertad y trata a la persona como una cosa. Nuestra lucha debe ser contra el racismo, la racialización que separa a la humanidad. Ir contra todo tipo de discriminación por raza, sexo, edad, religión como lo proclama la Declaración Universal de los Derechos Humanos y la Constitución del Perú.

Es inaudito que la Iglesia de la época haya permitido este desaguisado, nada menos que aquella que traía el mensaje de salvación, de liberación en base a la caridad, al amor entre todos los seres humanos.

Haití, primer país de la región en liberarse, recibió la peor de las respuestas de parte de países europeos, base de su estado actual de postración. Pese a ello, Haití fue el país que más creció en el año 2011, según datos de CEPAL.

Como vemos, sea con el mundo árabe como con el mundo africano, tenemos una relación muy estrecha y 
la hemos recibido a partir de la invasión hispana a nuestros territorios.

Hay en nosotros ascendencia africana, sea en el habla, en los comportamientos, en los genes, en la música, en la gastronomía. Tenemos relaciones diplomáticas con esos países.

No hay que olvidar que el patrono de las letras peruanas, don Ricardo Palma, poseía notorios rasgos africanos, lo que ha sido ocultado y tergiversado por una tradición historiográfica eurocéntrica, que ha blanqueado al insigne tradicionista peruano, en un Perú que hoy es reconocido por nuestra choledad triunfante, muy empren- dedora, trabajadora, altamente creativa y con gran capacidad y fortaleza de trabajo.

Entre la herencia andina, la criolla, la afro-descendiente; de sus 63 nacionalidades y tres grandes naciones va cuajando un Perú muy sólido en el este siglo XXI. Somos eminentemente mestizos, como mestizo es el mundo contemporáneo. En nuestras bases culturales, cabalga un José María Arguedas con un Nicomedes Santa Cruz y un Balumbrosio. Porque, como decía don Ricardo Palma, en el Perú quien no tiene de inga tiene de mandinga.

\section{NOTAS}

1 MONTOYA, Rodrigo, "Todas las culturas del Perú". Lima, Revista del Instituto de Investigaciones Histórico-Sociales de la Universidad Nacional mayor de San marcos, $N^{\circ} 6$, año 2000, pp. 7-24

2 ARANÍBAR, Carlos, "El principio de la dominación (1531-1580)". En "Nueva Historia General del Perú. Un compendio". Mosca Azul editores, primera edición, Lima, 1979, páginas 48-49.

3 TODOROV, Tzvetan, "La Conquista de América. El problema del otro”. Siglo XXI Editores, décimosexta edición en español, 2008.

4 MARIÁTEGUI, José Carlos, "Siete ensayos de interpretación de la realidad peruana". Vigésimasexta edición, Editora Amauta, abril de 1973, página 45.

5 VALCÁRCEL, Luis Eduardo, "Ruta Cultural del Perú”, Ediciones Nuevo Mundo, 1966, págs. 88-89.

6 MACERA, Pablo, "Feudalismo colonial americano: El caso de las haciendas peruanas" en Tomo 3 de sus "Trabajos de Historia”, Instituto Nacional de Cultura, Lima-1977, página 172.
7 FLORES GALINDO, Alberto, "Aristocracia y plebe. Lima, 1760-1830". Mosca Azul Editores, págs. 99-100.

8 QUIJANO, Aníbal, “iQué tal raza!”. Revista Venezolana de Economía y Ciencias Sociales, Vol. $6 \mathrm{~N}^{\circ} 1$, enero-abril del año 2000, páginas 37-45.

9 Líder negro de las asonadas libertarias centroamericanas presentado por el escritor cubano Alejo Carpentier en su novela "El reino de este mundo".

10 KAPSOLI, Wilfredo, "Sublevaciones de esclavos en el Perú. Siglo XVIII". Universidad Ricardo Palma, Dirección Universitaria de Investigación, Lima-Perú, 1975.

11 SANTOS DE SOUSA, Boaventura, "Refundación del Estado en América Latina. Perspectivas desde una epistemología del Sur". Publicado por el Instituto Internacional de Derecho y Sociedad, Programa Democracia y Transformación Global y la red Latinoamericana de Antropología Jurídica. Lima, julio de 2010. 